\title{
Effect of team-based learning on dental education in China: systematic review and meta-analysis
}

\author{
Jialing WANG ${ }^{1}$, Lei CHENG ${ }^{2}$, Mingyan JIANG ${ }^{1,3^{*}}$
}

\begin{abstract}
Background: Team-based learning (TBL) is a student-centered and teacher-directed teaching strategy. In contrast to the traditional lecture-based learning (LBL), TBL is committed to promoting self-directed learning and teamwork among students. A systematic review and meta-analysis of the literatures was performed to compare the teaching effects between TBL and LBL in dental students. Methods: Literature review was conducted from electronic databases including PubMed, Ovid, Web of science, Embase, China National Knowledge Infrastructure (CNKI), VIP and Wanfang Database up to January 12, 2020. Results: A total of 12 articles with 831 students were included in this meta-analysis. The results showed that students in the TBL group performed better than those in the LBL group in terms of theoretical grades (SMD: 1.29, $p=0.002,95 \%$ CI: 0.46-2.13), case analysis (SMD: $2.50, p<0.05,95 \% \mathrm{CI} 1.44-3.55$ ) and grades of practice ability (SMD: 1.90, $p=0.002,95 \% \mathrm{CI}: 0.68-3.12$ ). However, the results of each parameter followed a significantly high heterogeneity $\left(\mathrm{I}^{2}=96 \%, 92 \%, 93 \%\right.$, respectively). The quality of included studies was mostly good. Conclusion: TBL might be more effective to increase the absorption of theoretical knowledge and improve the ability of case analysis and practice. More well-designed and rigorous studies are required to validate this conclusion.
\end{abstract}

Keywords: dental education; Team-based learning; meta-analysis.

Practical Application: The pooled results of RCTs imply that the introduction of TBL contributes to the development of dental education in China. However, larger sample size are needed to validate this conclusion.

\section{Introduction}

In the past decades, medical education in China has been constantly reforming and innovating. To provide the teaching methods suitable for medical students, a variety of innovative teaching methods including team-based learning (TBL) has been introduced. TBL was a student-centered and teacher-directed teaching strategy in a specific group (Brich et al., 2017), firstly proposed by Dr Michaelsen in the early 1990s for use in business schools (McInerney \& Fink, 2003). The sequence and procedures in TBL embody the advantages of this learning method, such as advance assignment, individual readiness assurance test, team readiness assurance test, instructor clarification review, team discussion and defend their choice (Parmelee et al., 2012). For the complicated dental cases to be solved, it is imperative to give full play to the role of the team and respect the roles and strengths of each professional among the team (Jackson et al., 2018). Owing to the preparation before class and team-discussion, TBL emphasizes the self-regulation of learning and team-working (Morris, 2016). In addition, TBL appears to promote student participation and improve knowledge acquirement (Haidet et al., 2014). Lecture-based learning (LBL), as the main teaching method in China, emphasizes the delivery of syllabus and concept. LBL can increase the efficiency of classroom teaching, which is conducive to helping students master the contents of teaching materials comprehensively and accurately (Schaefer et al., 2018). However, the disadvantages of this teaching mode become increasingly prominent. Due to reliance on teachers, students may lack of initiative, clinical thinking and critical thinking (Gao et al., 2018), extremely detrimental to clinical problem solving and in-depth medical research. Although there are several articles confirming the superiority of TBL (Chen et al., 2018; Lang et al., 2019), widespread concensus has not been unified. Therefore, we conducted a systematic review and meta-analysis to compare the teaching effects between TBL and LBL for dental students, aiming to provide robust evidence for its potential application in dental education.

\section{Methods}

\subsection{Search strategy}

A comprehensive literature screening was conducted in PubMed, Ovid, Web of science, Embase, China National Knowledge Infrastructure (CNKI), VIP and Wanfang Database in January 12, 2020. The searching items consist of "Team-based learning" OR "TBL" AND "oral medicine" OR "stomatology" OR "dentistry" OR "Medicine, Oral" OR "oral education". We also sought potential eligible articles according to the reference list of potential eligible studies. The searching process was performed by two independent reviewers and each disagreement was arbitrated by the third reviewer. 


\subsection{Inclusion and exclusion criteria}

Studies were included if they met any of the following criteria.

i: the object of each study was Chinese dental students

ii: the study compared the teaching effect of TBL and TBL for dental students

iii: the study was a randomized controlled trials (RCT)

iiii: each group included 5 students at least

Any study matching any of the following criteria was excluded.

i: the experimental group or control group involved the joint application of other teaching modes, such as problem-based teaching (PBL), case-based learning (CBL) and flipping classroom, etc.

ii: the TBL method was not for Chinese dental students

iii: case report, conference abstract, experimental study, letter, comment, review

iiii: insufficient data or no available data

iiiii: just subjective effects instead of quantifiable indicators.

\subsection{Data extraction}

A double data extraction was performed independently. Any non-uniform data would be checked by the third investigator. After scrutinizing the full texts, two main parts of data were collected from eligible articles. The former part contained the first author, year of publishing, study region, study design, sample size of each group and specific course. The later one composed of quantified comparable outcome including theoretical grades, grades of case analysis and grades of practice ability. The nonhundred-mark system grades in one research were switched to hundred-mark system. In addition, if there was more than one outcome of the same type in an article, the one with more sufficient sample size would be selected.

\subsection{Quality assessment}

To make the outcomes robust, the Cochrane Handbook for Systemic Reviews of Interventions version 5.1.0 was applied to evaluate the quality of each study. Through "yes", "unclear" or "no", the selection bias, performance bias, detection bias, attrition bias, reporting bias and other bias of each included RCT were judged. When any disagreement appeared, the other one would attend to discuss until a consensus was obtained.

\subsection{Statistical analysis}

The included articles of this meta-analysis were pooled in Review Manager V.5.3 (The Cochrane Collaboration, Software Update, Oxford, UK). The combined data was described in the forest plots. Each continuous outcome was expressed by weight mean difference (WMD) and 95\% confidence interval (CI), respectively. Inconsistence index was implemented to measure the heterogeneity of all included studies. While heterogeneity $<50 \%$, a fixed-effects model was chosen to calculate the correlative data. Otherwise a random-effects model was applied. Statistical significance was defined by a $p$-value $<0.05$ for all outcome analyses. In addition, Begg's test and sensitivity analysis were conducted to assess the publication bias and the robustness of the main results, respectively. Any contradiction would be resolved by the third investigator.

\section{Results}

\subsection{Study selection and literature characteristics}

The specific method of literature searching and screening is shown in Figure 1. We identified a total of 991 literatures through electronic databases. After removing duplicates automatically and manually, the remaining 849 articles were available for preliminary review. A total of 724 literatures were excluded according to unsatisfactory literature types. Following scrutinizing the full texts, 12 RCTs were finally determined to be included in this meta-analysis. The study regions of the included RCTs were from China with publishing year from 2012 to 2018. A total of 831 students were included in this meta-analysis with 415 students in the TBL group and 416 students in the LBL group. Three of the 12 articles were taught in the general courses of dental science, including "histology and embryology", "first-aid knowledge", and "otolaryngology". The rest of articles involved specialized courses in oral medicine, such as "periodontology", "endodontic disease", "orthodontics", "oral mucosal diseases", as well as "oral surgery". All the baseline data are shown in Table 1.

Theoretical grades: Eleven of twelve articles (Li et al., 2012; Li et al., 2015; Ji et al., 2016; Pan et al., 2016; Sun et al., 2016; Wang et al., 2016; Qu et al., 2017; Cao, 2018; Gao et al., 2018; Liu et al., 2018; Wu et al., 2017) examined the theoretical grades of students in the TBL $(n=395)$ and LBL modes $(n=396)$, respectively. The results of this analysis showed that there was a significant difference between two groups $(p=0.002)$. The students who received the TBL mode performed better than students receiving the LBL mode (SMD: $1.29,95 \% \mathrm{CI}$ : $0.46-2.13)$. However, the heterogeneity of these studies was significant with $\mathrm{I}^{2}=96 \%(p<0.05)$, as illustrated in Figure 2 .

Grades of orthodontic case analysis: Six articles (Li et al., 2012; Gan et al., 2016; Ji et al., 2016; Sun et al., 2016; Wang et al., 2016; Gao et al., 2018) reported the grades of orthodontic case analysis. A total of 324 students participated in the comparison of teaching effect, with half of them in the TBL group and half in the LBL group. The students in the TBL group performed superior in the orthodontic case analysis than their counterparts receiving the LBL mode (SMD: 2.50, 95\%CI 1.44-3.55, $p<0.05)$. Similarly, a noteworthy heterogeneity was observed regarding the grades between two groups $\left(\mathrm{I}^{2}=92 \%, p<0.05\right)$, as shown in Figure 3 .

Grades of practice ability: A total of 108 students in the TBL group and 109 students in the LBL group were included in four articles (Gao et al., 2018; Li et al., 2015; Wang et al., 2016; Wu et al., 2017), respectively. The students receiving the TBL teaching method had a significantly higher likelihood 


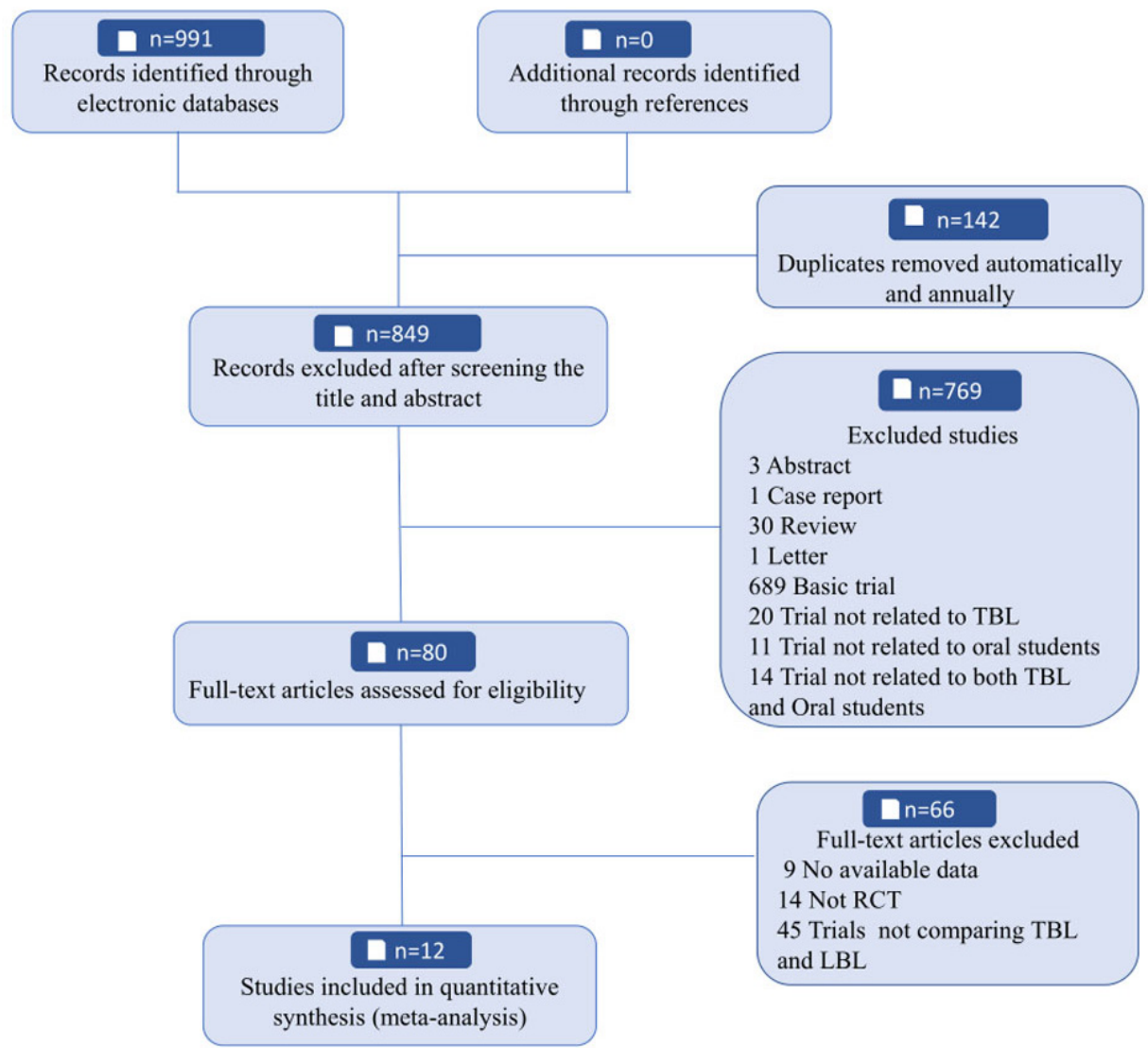

Figure 1. Literature searching and screening flow chart.

Table 1. The characteristics of included studies.

\begin{tabular}{|c|c|c|c|c|c|}
\hline Author year & Country & Teaching course & Study type & Students & $\begin{array}{c}\text { Number } \\
\left(\mathrm{TBL}^{\mathrm{a}} / \mathrm{LBL}^{\mathrm{b}}\right)\end{array}$ \\
\hline Yulin Cao 2018 & China & periodontology & $\mathrm{RCT}^{\mathrm{c}}$ & Dental students & $28 / 28$ \\
\hline Ning Gan 2016 & China & endodontic disease & RCT & Dental students & $20 / 20$ \\
\hline Xiang Gao 2018 & China & oral surgery & RCT & Dental students & $18 / 18$ \\
\hline Jia Ji 2016 & China & endodontic disease & RCT & Dental students & $50 / 50$ \\
\hline Lihua Li 2012 & China & orthodontics & RCT & Dental students & $24 / 24$ \\
\hline Zhenning Li 2015 & China & first-aid knowledge & RCT & Dental students & $30 / 30$ \\
\hline Danyang Liu 2018 & China & histology and embryology & RCT & Dental students & $81 / 81$ \\
\hline Chunling Pan2016 & China & periodontology & RCT & Dental students & $42 / 42$ \\
\hline Liu Qu 2017 & China & endodontic disease & RCT & Dental students & $32 / 32$ \\
\hline Yan Sun 2016 & China & oral mucosal diseases & RCT & Dental students & $30 / 30$ \\
\hline Bing Wang 2016 & China & otolaryngology & RCT & Dental students & $40 / 41$ \\
\hline Yan Wu 2017 & China & periodontology & RCT & Dental students & $20 / 20$ \\
\hline
\end{tabular}

a: Team-based learning; b: Lecture-based learning; c: randomized controlled trial.

to achieve satisfactory grades in the practice ability (SMD: $1.90,95 \%$ CI: $0.68-3.12, p=0.002$ ). It was worth noting that this difference was accompanied by high heterogeneity $\left(\mathrm{I}^{2}=93 \%, p<0.05\right)$, as illustrated in Figure 4 .

\subsection{Quality of included articles}

The risk of bias assessment of 12 included studies was shown in Figure 5. All the included articles were evaluated by the Cochrane Handbook for Systemic Reviews of Interventions and the main results were summarized in the Table 2. In general, the quality of the included articles was mostly good. Funnel plots of the theoretical knowledge, case analysis scores and practice ability were delineated to assess the publication bias (Figure 6-8). These 12 studies showed a low risk in random sequence generation (selection bias), detection bias, attrition bias, reporting bias and other bias. Nevertheless, all the studies showed a high risk of performance bias. In addition, 12 studies demonstrated unclearly in the allocation concealment. 


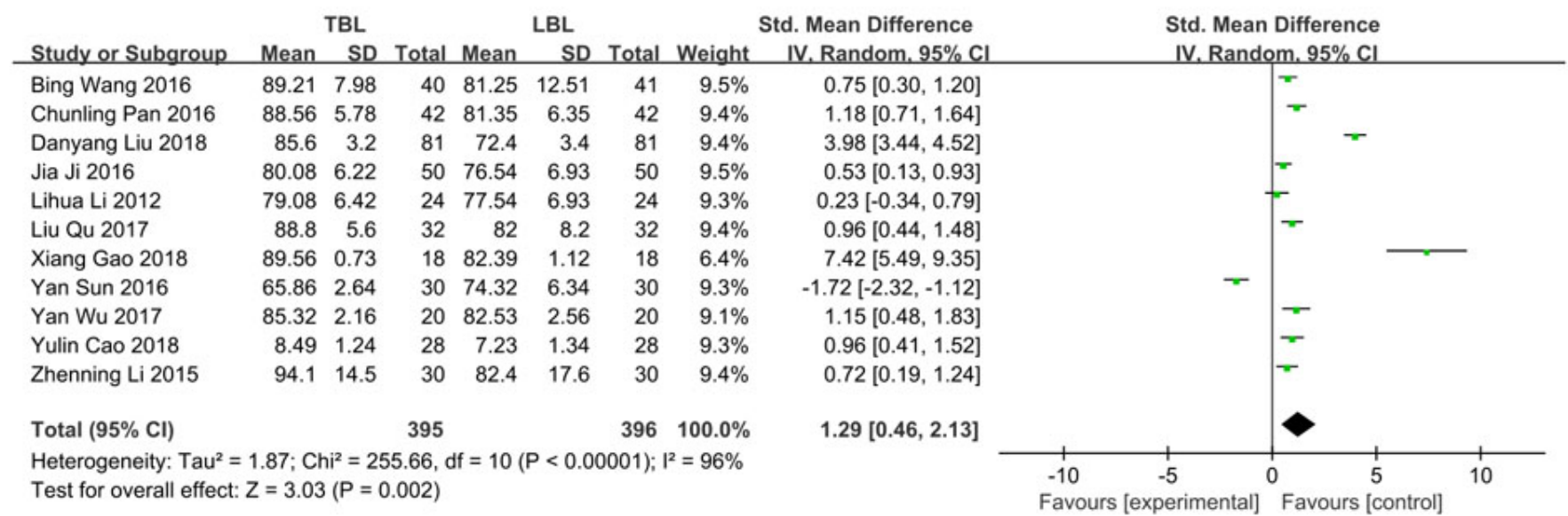

Figure 2. Forest plot of theoretical grade.

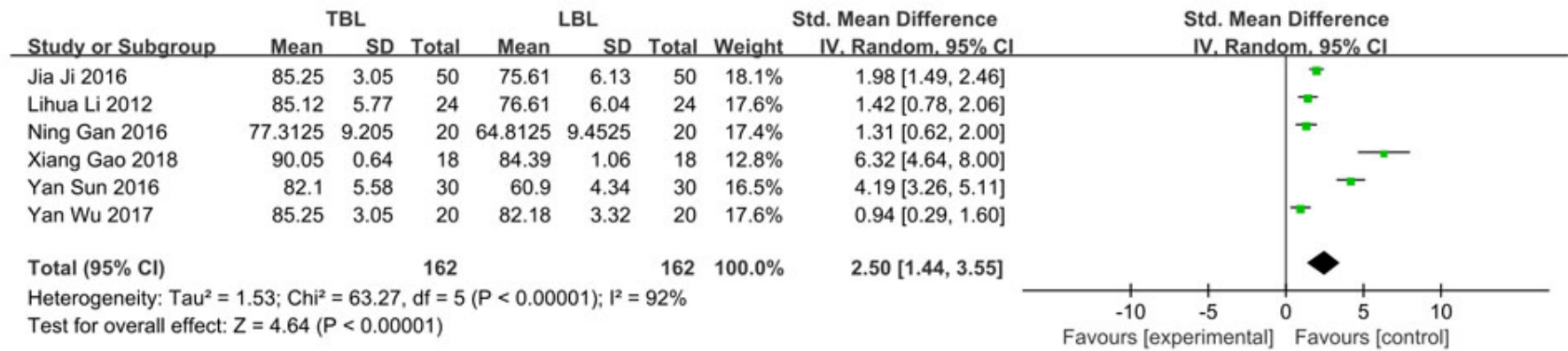

Figure 3. Forest plot of case analysis.

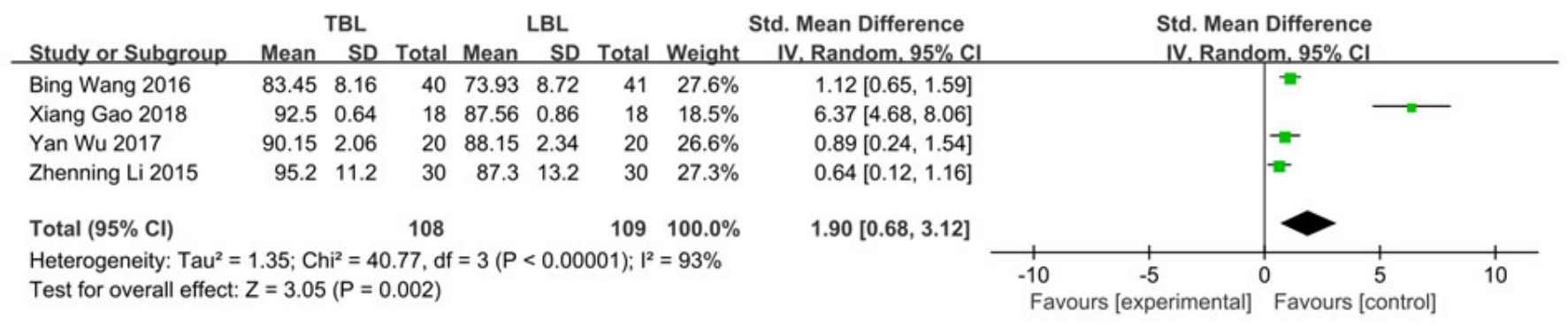

Figure 4. Forest plot of practice ability.

Table 2. Main results of the included studies.

\begin{tabular}{|c|c|c|c|c|c|c|c|}
\hline \multirow[b]{2}{*}{ Outcome } & \multirow{2}{*}{$\begin{array}{l}\mathrm{No}^{\mathrm{a}} . \\
\text { studies }\end{array}$} & \multirow[b]{2}{*}{$\begin{array}{c}\text { No. students } \\
\text { TBL }^{b} / \mathbf{L B L}^{c}\end{array}$} & \multicolumn{2}{|c|}{ Results } & \multicolumn{3}{|c|}{ Heterogeneity } \\
\hline & & & $\begin{array}{c}\text { SMD }^{\mathrm{d}} \\
\left(95 \% \mathrm{CI}^{\mathrm{e}}\right)\end{array}$ & $\mathbf{p}$ & $I^{2 \mathrm{f}}$ & $\mathrm{pH}^{\mathrm{g}}$ & Model \\
\hline Theoretical grades & 11 & $395 / 396$ & $1.290 .46-2.13$ & 0.002 & $96 \%$ & $<0.05$ & Random \\
\hline Grades of practice ability & 4 & $108 / 109$ & $1.900 .68-3.12$ & 0.002 & $93 \%$ & $<0.05$ & Random \\
\hline
\end{tabular}

a: number; b: Team-based learning; c: Lecture-based Learning d: standard mean difference; e: confidence interval; f: inconsistence index; g: P value of heterogeneity.

\section{Discussion}

\subsection{Summary of this meta-analysis}

In this article, the results of 12 studies were synthesized with a total of 831 students. The teaching effect significantly differed between the TBL and LBL groups. Students in the TBL group performed better than those in the LBL group in terms of theoretical grades, grades of orthodontic case analysis as well as grades of practice ability. Subgroup analysis showed TBL was the superior method whether in general or specialized courses. 


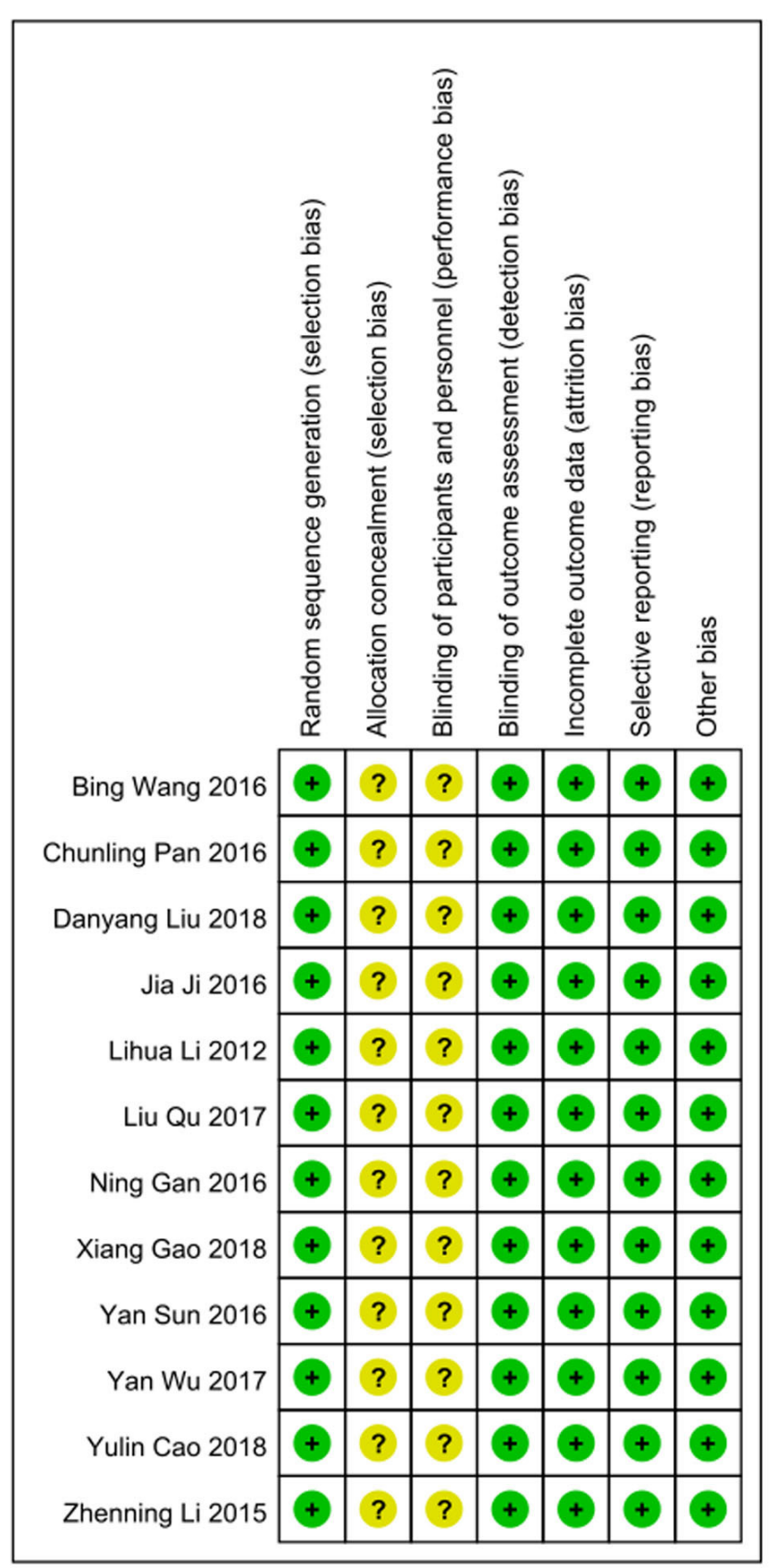

Figure 5. Risk of bias assessment of 12 included studies.

\subsection{Main findings and TBL}

Despite the rapid development of medical technology, basic clinical skills including theoretical knowledge, case analysis and operation skills, are still the most important and effective diagnostic tools for diseases. TBL provides a chance to make each student a dominant player rather than a passive receiver as in the LBL, therefore, students are willing to take the initiatives to master knowledge, promote the understanding and absorption of knowledge. LBL may not be appropriate as the total body of medical knowledge expands exponentially, teachers cannot simply impart knowledge as desired with low levels of learner

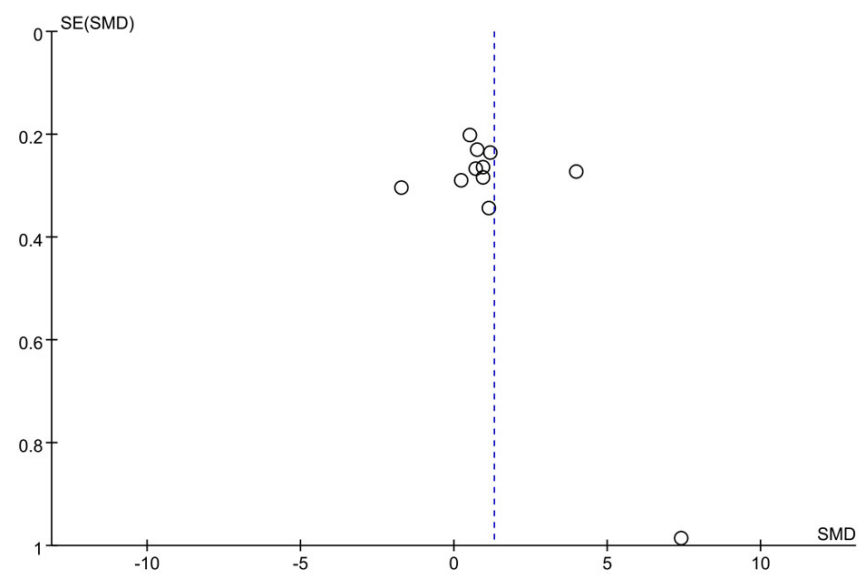

Figure 6. Funnel plot of theoretical grade.

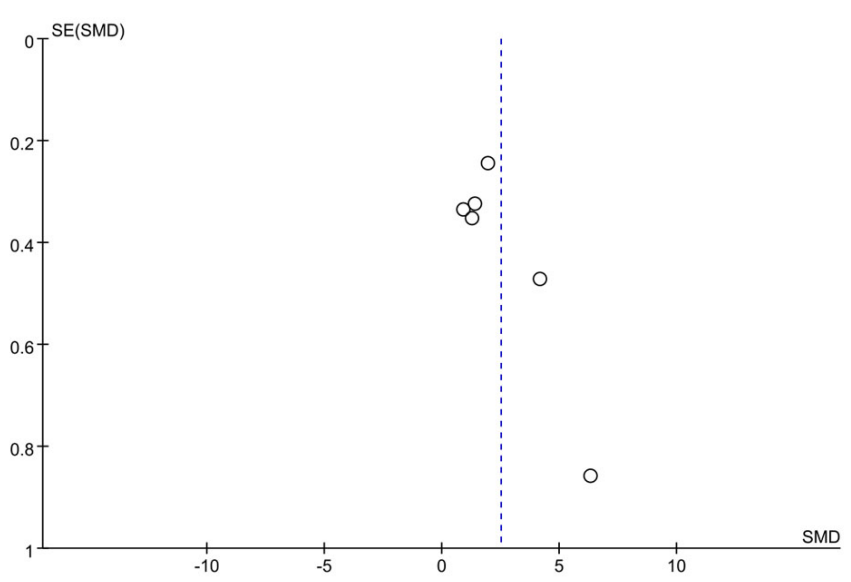

Figure 7. Funnel plot of case analysis.

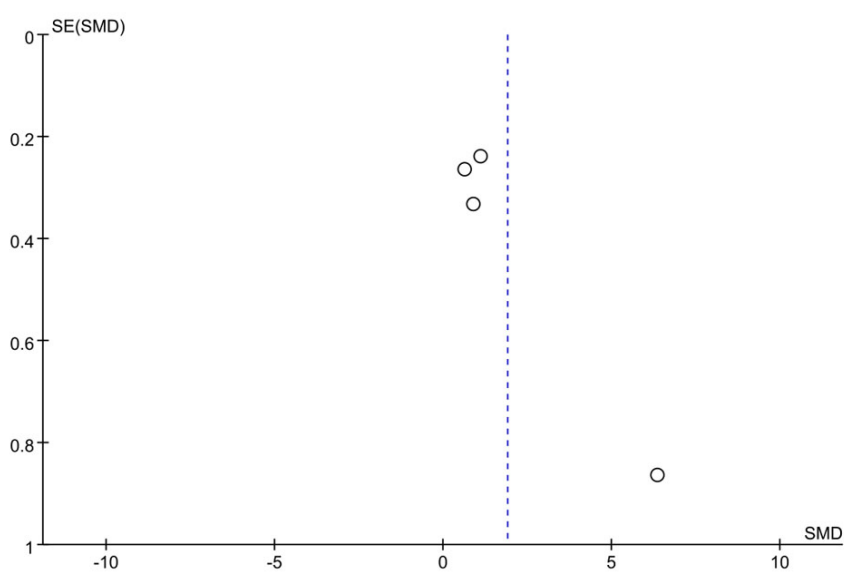

Figure 8. Funnel plot of practice ability.

engagement (Schaefer et al., 2018). Orthodontic case analysis emphasizes clinical and critical thinking, which are also the requirements for qualified physicians (Gleason et al., 2013). Since the students have consulted the materials in advance and mastered the knowledge firmly, they can quickly diagnose, analyze and propose a treatment plan for the case through comprehensive 
team discussion. In the six articles involving the outcome of grades of orthodontic case analysis, only one showed there was no significant difference between TBL and LBL (Wu et al., 2017), probably due to the use of bilingual teaching during the implementation of TBL. For the practice ability, teachers in the LBL mode often play videos, power point, or find a maximum of 2 students to show the correct practice, while it is difficult for everyone to acquire the sole direction owing to the limited teaching time. In the TBL mode, teachers have separate part to give instructions and team members also can help correct the wrong practices. Similarly, there was no significant difference between the TBL and LBL in terms of grades of practice ability in the study of Wu et al. (Wu et al., 2017) with the same explanation. Additionally, those who have self-direct learning have a higher satisfactory clinical practice (Noh \& Kim, 2019).

It takes efforts from some sides if we want to make full use of the advantages of TBL. Firstly, leadership in dental education must be cognizant of all relevant advances, changes and trends in teaching. They need to not only introduce the effective teaching mode, but also encourage and motivate those delivering educational programs to accept and adopt the new model, while responding to student feedback, and educational outcomes and assessments (Lynch et al., 2019). Secondly, TBL expects teachers to change the traditional teaching concept and transform the status from teaching of absolute guidance to important participant and organizer, which requires teachers to be familiar with the teaching content and master the rhythm of the course to offer a relaxing and ordered environment for students. More importantly, since TBL requires an instructor for each group, it requires a sufficient quantity of experienced teacher. Nevertheless, this seems a long way because there is no research related to TBL in some medical professional courses (Poeppelman et al., 2016). Prior to the TBL course, students should be given enough time to preview the materials and prevent them from not participating in the discussion due to insufficient preparation, which directly affects the teaching quality. Additionally, when grouping, the personality and ability differences of students should be fully considered to avoid affecting the quality of class due to insufficient communication.

Internationally, the increasingly strict standard on dentists not only require professional knowledge, but also the ability of problem-solving and self-directed learning, critical thinking, team performance and the willingness and ability to learn throughout life to ultimately become experts (2019). Rola et al. identified the priority of national dental education research and the first three are role of assessments in identifying competence, undergraduate curriculum prepares for practice and promotion of teamwork within the dental team (Ajjawi et al., 2017). To meet these requirements, a variety of innovative teaching methods have been applied including TBL, problem-based learning (PBL), case-based learning and flipped classroom, etc. PBL develops earlier than TBL and has been adopted for a long time in some schools (Kinkade, 2005). Moreover, a comparison in 2002 showed that students in the PBL group enjoy their courses to a greater extent, based on the at least same success in the standardized tests in contrast with students in the LBL group (Michel et al., 2002). However, TBL seems to gain more popularity in medical education compared with PBL in recent years (Parmelee et al.,
2012; Burgess et al., 2017), possibly because students are assigned to smaller groups in TBL and thus present greater participation, discussion and collaboration (Wiener et al., 2009). Through discussing clinical cases in groups, CBL aims to render students independent, able to apply concepts learned in class and search for information on their own, as they will have to do in their future employment (Theodosiou et al., 2012). In a dental school, students applied their knowledge better in the CBL course, whereas obtained higher knowledge scores in the TBL course (Haley et al., 2020). There is increasing evidence suggesting that a combination of several teaching methods can exert a beneficial teaching effect upon students (Kumar \& Gadbury-Amyot, 2012; Della Ratta, 2015; Estai \& Bunt, 2016), indicating that medical education takes full account of the development of students.

\subsection{High heterogeneity}

Heterogeneity must also be discussed in this article since three studies yield high heterogeneity. Multiple factors might contribute to the high heterogeneity as follows. Firstly, definition and comprehension are intimately associated with the quality of TBL. Therefore, TBL might be executed in different procedures and present different quality. Secondly, recognition and acceptance of students for TBL or LBL will also affect their performance in the corresponding courses, thus presenting a difference. Additionally, personal characteristics of students may have an effect, owing to the need for teamwork and self-expression during the process. Thirdly, the course selected in each study is diverse and it is not easy to control the degree of difficulty. Fourthly, the consistency of measurement method is an important cause of heterogeneity, which directly affects the primary data included in this article. Fifthly, instructors may cause a difference whether in the TBL or LBL group. In the TBL group, knowledge mastery of students depends partly on whether the instructors can give enough and efficacious guidance to the students. In the LBL group, the teaching style of teachers matters. Too rigid lecture will hinder the interests of students in learning, thus deceasing the learning efficiency.

\subsection{Strengths and limitations}

To our knowledge, this is the first meta-analysis focusing on comparing the teaching effects between TBL and LBL for dental students. The main strengths of our work are as follows: (i) We evaluated the effects of two different teaching methods from three aspects: theoretical grades, grades of orthodontic case analysis as well as grades of practice ability. This was comprehensive and was in line with the requirements of dental students. (ii) The positive results in this meta-analysis provided evidence to confirm the superiority of TBL and this might promote the development of TBL in China. Nevertheless, there are still some limitations in this meta-analysis, study selection, the incomplete information of patients and heterogeneity. (i) All included studies were conducted in China. Therefore, the conclusion of this meta-analysis might be more applicable to Chinese medical education and a larger scale study involving different countries is needed. (ii) This study included 12 RCTs with 831 dental students and the sample size was relatively small. A plausible explanation was that TBL remains in the stage of 
exploratory application. Hence, the number of students included in the RCTs is limited. (iii) Only a few studies mentioned the comparability of baseline data, whether there was a difference between two groups before intervention was implemented remains to be unravelled.

The pooled results of 12 RCTs imply that TBL might help dental students increase their theoretical grades, grades of orthodontic case analysis as well as grades of practice ability compared with LBL teaching mode. However, considering the high heterogeneity and non-uniform intervention, more rigorous and uniform experimental design and larger sample size are needed to validate this conclusion. Taken together, the introduction of TBL contributes to the development of medical education in China.

\section{List of abbreviations}

TBL Team-based learning

CNKI China National Knowledge Infrastructure

RCT randomized controlled trials

PBL problem-based learning

CBL case-based learning

WMD weight mean difference

CI confidence interval

\section{Ethics approval and consent to participate}

All procedures performed in studies involving human participants were in accordance with the ethical standards of the institutional and national research committee and with the 1964 Helsinki declaration and its later amendments or comparable ethical standards. This study is approved by relevant Ethics Committee.Written informed consent was obtained.

\section{Competing interests}

The authors declare that they have no competing interest.

\section{Availability of data and materials}

The raw data for this study are available upon reasonable request to the corresponding author.

\section{Funding}

This study was supported by The Health and Family Planning Commission of Sichuan Province (grant no. 150106).

\section{Authors' contributions}

Jiang Mingyan carried out the guarantor of integrity of the entire study, study design, clinical studies, data acquisition, data analysis, manuscript preparation, editing and manuscript review; Wang Jialing was dedicated to the literature research, clinical studies, data acquisition, data analysis, statistical analysis and manuscript preparation; Cheng Lei was involved in the study concepts, definition of intellectual content, data acquisition and manuscript preparation. All authors have read and approved this article.

\section{References}

Ajjawi, R., Barton, K. L., Dennis, A. A., \& Rees, C. E. (2017). Developing a national dental education research strategy: priorities, barriers and enablers. BMJ Open, 7(3), e013129. http://dx.doi.org/10.1136/ bmjopen-2016-013129. PMid:28360237.

Brich, J., Jost, M., Brüstle, P., Giesler, M., \& Rijntjes, M. (2017). Teaching neurology to medical students with a simplified version of teambased learning. Neurology, 89(6), 616-622. http://dx.doi.org/10.1212/ WNL.0000000000004211. PMid:28701497.

Burgess, A., Bleasel, J., Haq, I., Roberts, C., Garsia, R., Robertson, T., \& Mellis, C. (2017). Team-based learning (TBL) in the medical curriculum: better than PBL? BMC Medical Education, 17(1), 243. http://dx.doi.org/10.1186/s12909-017-1068-z. PMid:29221459.

Cao, Y. (2018). Application of TBL in periodontal disease teaching. Contemporary Education Research and Teaching Practice, 9, 846. http://dx.doi.org/10.3969/j.issn.2095-6711.2018.09.628.

Chen, M., Ni, C., Hu, Y., Wang, M., Liu, L., Ji, X., Chu, H., Wu, W., Lu, C., Wang, S., Wang, S., Zhao, L., Li, Z., Zhu, H., Wang, J., Xia, Y., \& Wang, X. (2018). Meta-analysis on the effectiveness of team-based learning on medical education in China. BMC Medical Education, 18(1), 77. http://dx.doi.org/10.1186/s12909-018-1179-1. PMid:29636039.

Della Ratta, C. B. (2015). Flipping the classroom with team-based learning in undergraduate nursing education. Nurse Educator, 40(2), 71-74. http://dx.doi.org/10.1097/NNE.0000000000000112. PMid:25402712.

Estai, M., \& Bunt, S. (2016). Best teaching practices in anatomy education: A critical review. Annals of Anatomy, 208, 151-157. http://dx.doi. org/10.1016/j.aanat.2016.02.010. PMid:26996541.

Gan, N., Li, Y., Wan, Z., \& Zhou, Z. (2016). Team-based learning in Conservative Dentistry and Endodontics case analysis teaching. Education Teaching Forum, 05, 249-251. http://dx.doi.org/10.3969/j. issn.1674-9324.2016.05.116.

Gao, X., Li, Y., Qiu, L. H., Wang, T., \& Xiao, S. S. (2018). Application of TBL method in postgraduate students teaching in oral and maxillofacial surgery in Chinese Stomatological Association. In The second annual academic meeting of the professional committee of stomatology education of Chinese Stomatological Association (pp. 59-65). Wuhan, China: Chinese Stomatological Association.

Gleason, B. L., Gaebelein, C. J., Grice, G. R., Crannage, A. J., Weck, M., Hurd, P., Walter, B., \& Duncan, W. (2013). Assessment of students' critical-thinking and problem-solving abilities across a 6-year doctor of pharmacy program. American Journal of Pharmaceutical Education, 77(8), 166. http://dx.doi.org/10.5688/ajpe778166. PMid:24159207.

Haidet, P., Kubitz, K., \& McCormack, W. T. (2014). Analysis of the Team-Based Learning Literature: TBL Comes of Age. Journal on Excellence in College Teaching, 25(3-4), 303-333. PMid:26568668.

Haley, C. M., Brown, B., Koerber, A., Nicholas, C. L., \& Belcher, A. (2020). Comparing Case-Based with Team-Based Learning: Dental Students' Satisfaction, Level of Learning, and Resources Needed. Journal of Dental Education, 84(4), 486-494. http://dx.doi. org/10.21815/JDE.019.190. PMid:32314392.

Jackson, S. C., Bilich, L. A., \& Skuza, N. (2018). The Benefits and Challenges of Collaborative Learning: Educating Dental and Dental Hygiene Students Together. Journal of Dental Education, 82(12), 1279-1286. http://dx.doi.org/10.21815/JDE.018.134. PMid:30504465. 
Ji, J., Kang, Y., An, H. P., \& Bai, M. H. (2016). The Application of Team-bmmd Learning Teaching Method in the Clinical Practice of Stomatology. Chinese Medicine Modern Distance Education of China, 14(14), 11-13. http://dx.doi.org/10.3969/j.issn.1672-2779.2016.14.006.

Kinkade, S. (2005). A snapshot of the status of problem-based learning in U. S. medical schools, 2003-04. Academic Medicine, 80(3), 300-301. http://dx.doi.org/10.1097/00001888-200503000-00021. PMid:15734817.

Kumar, V., \& Gadbury-Amyot, C. C. (2012). A case-based and teambased learning model in oral and maxillofacial radiology. Journal of Dental Education, 76(3), 330-337. http://dx.doi.org/10.1002/j.00220337.2012.76.3.tb05262.x. PMid:22383601.

Lang, B., Zhang, L., Lin, Y., Han, L., Zhang, C., \& Liu, Y. (2019). Teambased learning pedagogy enhances the quality of Chinese pharmacy education: a systematic review and meta-analysis. BMC Medical Education, 19(1), 286. http://dx.doi.org/10.1186/s12909-019-17246. PMid:31357986.

Li, L., Mi, F., \& Chen D. (2012). Application and effect evaluation of team based learning in oral orthodontic clinical case analysis teaching. Journal of Modern Medicine and Health, 28(19), 2915-2916+2918. http://dx.doi.org/cnki:sun:xyws.0.2012-19-016.

Li, Z., Zhou, Q., \& Sun, C. (2015). The application of Team-based learning in first aid knowledge teaching. National Annual Conference Of Stomatology Education (pp. 147-151). Urumqi, China: Chinese Stomatological Association.

Liu, D., Yao, H., Sun, L., Zhang, H., Lang, W., Wang, Y., \& Li, L. (2018). Effect of TBL Teaching Method in Experimental Teaching of Histology and Embryology. China Continuing Medical Education, 10(31), 48-50. http://dx.doi.org/10.3969/j.issn.1674-9308.2018.31.023.

Lynch, C. D., Blum, I. R., \& Wilson, N. H. F. (2019). Leadership in dental education. Journal of Dentistry, 87, 7-9. http://dx.doi.org/10.1016/j. jdent.2019.07.011. PMid:31330164.

McInerney, M. J., \& Fink, L. D. (2003). Team-based learning enhances long-term retention and critical thinking in an undergraduate microbial physiology course. Microbiology Education, 4(1), 3-12. http://dx.doi.org/10.1128/me.4.1.3-12.2003. PMid:23653548.

Michel, M. C., Bischoff, A., \& Jakobs, K. H. (2002). Comparison of problem-and lecture-based pharmacology teaching. Trends in Pharmacological Sciences, 23(4), 168-170. http://dx.doi.org/10.1016/ S0165-6147(00)01940-4. PMid:11931991.

Morris, J. (2016). The use of team-based learning in a second year undergraduate pre-registration nursing course on evidence-informed decision making. Nurse Education in Practice, 21, 23-28. http:// dx.doi.org/10.1016/j.nepr.2016.09.005. PMid:27690246.
Noh, G. O., \& Kim, D. H. (2019). Effectiveness of a self-directed learning program using blended coaching among nursing students in clinical practice: a quasi-experimental research design. $B M C$ Medical Education, 19(1), 225. http://dx.doi.org/10.1186/s12909019-1672-1. PMid:31234843.

Pan, C., Chang, C., Tan, L., \& Pan, Y. (2016). Application of the TeamBased Learning teaching model in periodontology. Stomatology, 36(04), 358-360.http://dx.doi.org/10.13591/j.cnki.kqyx.2016.04.017.

Parmelee, D., Michaelsen, L., Cook, S., \& Hudes, P. (2012). Team-based learning: a practical guide: AMEE guide no. 65. Medical Teacher, 34(5), e275-e287. http://dx.doi.org/10.3109/0142159X.2012.651179. PMid:22471941.

Poeppelman, R. S., Liebert, C. A., Vegas, D. B., Germann, C. A., \& Volerman, A. (2016). A Narrative Review and Novel Framework for Application of Team-Based Learning in Graduate Medical Education. Journal of Graduate Medical Education, 8(4), 510-517. http://dx.doi.org/10.4300/JGME-D-15-00516.1. PMid:27777660.

Qu, L., Yan, L., Qiu, L., \& Xue, M. (2017). Using TBL in endodonfics teaching. China Higher Medical Education, (11), 112-113. http:// dx.doi.org/10.3969/j.issn.1002-1701.2017.11.057.

Schaefer, S. M., Dominguez, M., \& Moeller, J. J. (2018). The Future of the Lecture in Neurology Education. Seminars in Neurology, 38(04), 418-427. http://dx.doi.org/10.1055/s-0038-1667042. PMid:30125896.

Sun, Y., Kang, Y., Zhang, Y., \& Wen, Y. (2016). The application of LBL and TBL in oral mucosal disease teaching. China Higher Medical Education, (10), 97-98. http://dx.doi.org/10.3969/j.issn.10021701.2016.10.052.

Theodosiou, M., Rennard, J. P., \& Amir-Aslani, A. (2012). Theory to practice: real-world case-based learning for management degrees. Nature Biotechnology, 30(9), 894-895. http://dx.doi.org/10.1038/ nbt.2362. PMid:22965063.

Wang, B., Yao, H., \& Shu, Y. (2016). Application of Team-based learning in the teaching of otolaryngology. Jianyan Yixue Yu Linchuang, 13(08), 1148-1149. http://dx.doi.org/10.3969/j.issn.1672-9455.2016.08.059.

Wiener, H., Plass, H., \& Marz, R. (2009). Team-based learning in intensive course format for first-year medical students. Croatian Medical Journal, 50(1), 69-76. http://dx.doi.org/10.3325/cmj.2009.50.69. PMid:19260147.

Wu, Y., Tang, W., Wu, J., Wang, W., Jing, Z., \& Li, L. (2017). The exploration of TBL in bilingual teaching of periodontal disease. China Higher Medical Education, (04), 105-106. http://dx.doi. org/10.3969/j.issn.1002-1701.2017.04.055. 